\title{
MicroRNA Expression Profiles in Papillary Thyroid Carcinoma, Benign Thyroid Nodules and Healthy Controls
}

\author{
Ebru Esin Yoruker1, Duygu Terzioglu² ${ }^{2}$ Serkan Teksoz ${ }^{3}$, Fatma Ezel Uslu², Ugur Gezer ${ }^{1}$, Nejat Dalay ${ }^{\circledR}$ \\ 1. Oncology Institute, Department of Basic Oncology, Istanbul University, Istanbul, Turkey; \\ 2. Cerrahpasa Faculty of Medicine, Department of Biochemistry, Istanbul University, Istanbul, Turkey; \\ 3. Cerrahpasa Faculty of Medicine, Department of Surgery, Istanbul University, Istanbul, Turkey. \\ $\triangle$ Corresponding author: Prof. Dr. Nejat Dalay, I.U. Oncology Institute, 34093 Capa, Istanbul, Turkey. Phone: $902124142434-34182$ e-mail: ndalay@yahoo.com.
}

( ) Ivyspring International Publisher. Reproduction is permitted for personal, noncommercial use, provided that the article is in whole, unmodified, and properly cited. See http://ivyspring.com/terms for terms and conditions.

Received: 2015.09.18; Accepted: 2016.03.13; Published: 2016.04.26

\begin{abstract}
MicroRNAs (miRNAs) represent a class of short endogenous non-coding RNAs that negatively regulate gene expression at the post-transcriptional level in many biological processes, including proliferation, differentiation, stress response and apoptosis.

In this study we analyzed a set of seven miRNA molecules in sera of patients with papillary thyroid cancer, multinodular goiter and healthy controls to identify miRNA molecules that may have utility as markers for PTC.

MiR-21 serum levels in the preoperative PTC and MG groups were significantly higher than the control group. Likewise, postoperative levels of miR-151-5p, miR-221 and miR-222 were significantly lower in patients with PTC. When serum miRNA levels were evaluated according to stage, postoperative levels of miR-151-5p and miR-222 were significantly lower in patients with advanced stages of the disease. The miRNA levels were also found associated with the size of the primary tumor. Our data imply that specific miRNA molecules which are differentially expressed in thyroid tumors may play role in the development of papillary thyroid carcinoma.
\end{abstract}

Key words: miRNA, expression, papillary thyroid cancer.

\section{Introduction}

Thyroid cancer is the most rapidly increasing cancer among women and the second among men [1]. The number of new cases of thyroid cancer is 12.2 per 100,000 and the median age at diagnosis is 50 years. The disease is more common in women than men and among those with a family history of thyroid disease. Papillary thyroid carcinoma (PTC) accounts for approximately $80 \%$ of thyroid cancer cases. The prognosis of PTC is very good for the majority of patients. However, recurrences are observed in approximately $30 \%$ of the patients and increasing incidence of the disease warrants further analysis of the molecular characteristics. Fine needle aspiration biopsy is currently the most useful diagnostic method to evaluate a thyroid nodule but $30 \%$ of the biopsies cannot provide reliable information on the risk of recurrences. Although somatic mutations act as drivers for approximately $70 \%$ of the papillary carcinomas analysis of the known mutations does also not provide information on the recurrence and development of metastases [2,3]. Therefore, additional markers to identify and distinguish the tumors with high risk of recurrence are necessary [4]. On the other hand, multinodular goiter is the enlargement of the thyroid gland and is not associated with malignancy $[5,6]$. Recent studies have revealed distinct abnormalities in the key pathways in thyroid tumors such as aberrations in epigenetic silencing, alternative 
splicing, aberrant gene expression patterns and single-nucleotide polymorphisms associated with susceptibility [7-10].

MicroRNAs are short endogenous non-coding molecules that regulate gene expression at the post-transcriptional level and can activate multiple oncogenic pathways in different forms of cancer. miRNAs bind to their corresponding transcripts interfering with their translation or inducing their degradation, thereby modulating all cellular pathways which are dysregulated in cancer. Aberrant miRNA expression is frequently observed in human cancer and has been associated with tumor development. Therefore, differential expression of miRNAs is considered a tumor-specific event which may reflect tumor behavior. Accordingly, some miRNAs have been reported to have clinical utility as prognostic markers or tools to evaluate the stage or progression of the disease [11-13]. Several studies suggest that miRNAs in sera may also act as potential biomarkers for different cancer types [14-16].

Recent studies aimed to evaluate specific miRNA expression profiles in thyroid cancer [17-19]. It has been shown that persistent expression of miRNAs may be crucial to maintain tumorigenesis [20]. However, although differential expression of several miRNA molecules has been reported in thyroid cancer the results in the literature are highly inconsistent. Among the relatively high numbers of miRNA molecules very few have been found to have prognostic or diagnostic utility and only few studies have investigated the role of miRNAs in PTC [21,22]. Furthermore, the majority of these studies have low statistical power due to the heterogeneity and limited numbers of the study groups [23].

Selected miRNAs have frequently been reported as being up- or downregulated in PTC compared with healthy controls [14,24-25]. The objective of this study was to evaluate several potential miRNA molecules as markers which may help in distinguishing PTC from benign tumors and identifying high and low risk tumors. We compared expression levels of seven different microRNA molecules in serum samples from a homogeneous group of patients with the same histopathological type of thyroid tumor.

\section{Materials and Methods}

A total of 86 subjects including 31 patients with papillary thyroid cancer who were treated at the University of Istanbul, Cerrahpasa Medical Faculty, 31 patients with multinodular goiter and 24 healthy controls were taken into the study. Serum samples from the patients with PTC were obtained prior to and five weeks after the surgery. Data regarding patient demographics (age, gender) and primary tumor histopathology (tumor size, lymph node metastasis, TNM stage) were obtained by reviewing the patients' medical records. The study protocol was approved by the Ethical Committee of Istanbul Faculty of Medicine.

All sera were immediately stored at $-80^{\circ} \mathrm{C}$ until RNA isolation. Circulating RNA molecules were isolated from sera using the Tripure Isolation reagent (Roche, Mannheim, Germany). Briefly, $200 \mu 1$ serum was mixed with $800 \mu$ l Tripure reagent and incubated at room temperature for complete dissociation of the nucleoprotein complexes. Following incubation, 0,2 $\mathrm{ml}$ chloroform was added and the samples were incubated at room temperature for $15 \mathrm{~min}$. After centrifugation at $12000 \mathrm{~g}$ for $15 \mathrm{~min}$, the upper phase was transferred into Eppendorf tubes and 0,5 ml isopropanol was added. The mixture was incubated at room temperature for $10 \mathrm{~min}$ and centrifuged at 12000 $\mathrm{g}$ for $10 \mathrm{~min}$. The supernatant was discarded and the RNA-containing pellet was washed with $75 \%$ ethanol. Following washing, the mixture was centrifuged at $7500 \mathrm{~g}$ for $5 \mathrm{~min}$. The supernatant was removed, air dried and resuspended in RNAse-free water. The RNA sample was incubated at $55-60{ }^{\circ} \mathrm{C}$ and was stored in $-80^{\circ} \mathrm{C}$ until use.

Complementary DNA (cDNA) was synthesized using the miScript Reverse Transcription Kit (Qiagen, Valencia, CA, USA) according to the instructions of the manufacturer. During the first step of the reaction a poly-A tail was added to the 3 '-end of the RNA molecules, while in the second step, cDNA was synthesized by the reverse transcriptase. cDNA synthesis was performed at $37^{\circ} \mathrm{C}$ for $60 \mathrm{~min}$, and the reaction was terminated by incubation at $95^{\circ} \mathrm{C}$ for 5 min.

Quantification of the miRNAs was performed using the miScript Primer Assay (Qiagen, Valencia, CA, USA) which includes a universal primer specific to the poly-A tail and a miRNA-specific primer. The microRNA primers used in the study are presented in Table 1. SYBR Green (Qiagen, Valencia, CA, USA) was used as the fluorescent label for quantification and miR-16 was used as reference for normalization of the expression levels of the miRNA panel. Quantitative PCR was performed using the LightCycler 480 platform (Roche Diagnostics, Mannheim, Germany). The PCR reaction included a fast start step of $15 \mathrm{~min}$ at $95^{\circ} \mathrm{C}$ followed by 45 cycles of amplification where each cycle consisted of denaturation at $94^{\circ} \mathrm{C}$ for $15 \mathrm{~s}$, annealing at $55^{\circ} \mathrm{C}$ for $30 \mathrm{~s}$ and elongation at $70^{\circ} \mathrm{C}$ for $30 \mathrm{~s}$. Melting curve analysis was performed to verify the identity and specificity of the PCR products. Relative miRNA levels were determined by calculating the ratio of the target and reference amplicons. Samples with a value of $\mathrm{Ct}>40$ were 
considered negative. Specimens displaying very low miR-16 expression levels were excluded from the study.

Statistical analysis was performed using the SPSS v15 statistical package program. All statistical analyses were performed using the Mann-Whitney U for intergroup and the $t$ test for intragroup analyses. $p<0.05$ was considered as statistically significant.

Table 1: The microRNA molecules analyzed in the study.

\begin{tabular}{lll}
\hline miRNA & Cat Nr. & miR-Base Accession Nr. \\
\hline Hs_miR-222_2 & MS00007609 & MIMAT0000279 \\
Hs_miR-146b_1 & MS00003542 & MIMAT0002809 \\
Hs_miR-21_2 & MS00009079 & MIMAT0000076 \\
Hs_miR-31_1 & MS00003290 & MIMAT0000089 \\
Hs_miR-221_1 & MS00003857 & MIMAT0000278 \\
Hs_miR-151-5p_1 & MS00008764 & MIMAT0004697 \\
Hs_let-7e_3 & MS00031227 & MIMAT0000066 \\
\hline
\end{tabular}

\section{Results}

We analyzed the expression of seven different miRNA molecules for differences in aberrant miRNA expression and in terms of their utility to distinguish PTC from benign thyroid lesions by quantitative real-time PCR. The distribution of the miRNA levels in the disease groups and healthy individuals are shown in Figure 1. miR-222, miR-31, miR-151-5p and let-7 miRNA levels were markedly higher and miR-21 levels were lower in the patients with PTC when compared with the healthy controls and benign tumors. However, a significant difference between papillary tumors and multinodular goitre was observed only for miR-222 ( $p=0.018)$. Between-groups analyses comparing the levels of the miRNA molecules in all three groups revealed a significant difference between the miR-21 levels (Table 2). Pairwise comparison revealed that serum miR-21 levels in the preoperative PTC $(p=0.002)$ and MG $(p=0.007)$ groups were significantly lower than the control group while no difference was observed between the disease groups $(p=0.35)$. When the differences between the pre- and postoperative patients were compared significantly lower expression of miR-221, miR-222, miR-151-5p and miR-31 were observed in the patients with PTC after removal of the tumors (Table 3).

Evaluation of serum miRNA levels according to the stage showed a significant decline in the postoperative miR-151-5p levels in advanced stages (Stage III+IV) when compared with the preoperative levels. Likewise, postoperative serum miR-222 levels in patients with stage III+IV disease were significantly lower when compared to preoperative levels (Table 4). Serum miRNA levels in the patients with PTC were also evaluated according to the tumor size. Postoperative miR-222 levels were significantly lower than preoperative levels for all tumors (Table 5). Preoperative miR-221 levels in patients with tumors larger than $2 \mathrm{~cm}$ were significantly lower than the patients with smaller tumors. Postoperative miR-146b levels were higher in patients with tumors larger than $2 \mathrm{~cm}$ while postoperative miR-151-5p and miR-221 levels were lower in tumors smaller than $2 \mathrm{~cm}$.

Table 2: The miRNA levels in the disease groups.

\begin{tabular}{lllll}
\hline Preop & PTC & MNG & Control & $\mathrm{p}$ \\
\cline { 2 - 4 } & Mean \pm SD & Mean \pm SD & Mean \pm SD & \\
\hline miR-146b & $1.11 \pm 1.53$ & $1.05 \pm 0.58$ & $1.06 \pm 0.78$ & 0.31 \\
miR-21 & $0.02 \pm 0.11$ & $0.029 \pm 0.09$ & $0.09 \pm 0.12$ & $0.002^{* *}$ \\
miR-31 & $0.52 \pm 0.76$ & $0.36 \pm 0.33$ & $0.37 \pm 0.35$ & 0.899 \\
miR-151-5p & $0.18 \pm 0.25$ & $0.12 \pm 0.33$ & $0.12 \pm 0.3$ & 0.07 \\
miR-221 & $0.14 \pm 0.24$ & $0.16 \pm 0.27$ & $0.17 \pm 0.22$ & 0.433 \\
miR-222 & $2.19 \pm 2.49$ & $1.01 \pm 0.97$ & $0.59 \pm 0.59$ & 0.3 \\
let7e & $0.012 \pm 0.06$ & $0.0009 \pm 0.004$ & $0.0008 \pm 0.004$ & 0.771 \\
\hline Kruskal-Wallis ** $<0.01$ & & &
\end{tabular}

Kruskal-Wallis ** $\mathrm{p}<0.01$

Table 3: The levels of the miRNA molecules in the pre- and postoperative patients with PTC.

\begin{tabular}{llll}
\hline PTC Group & Preop & Postop & $\mathrm{p}$ \\
\cline { 2 - 3 } & Mean \pm SD & Mean \pm SD & \\
\hline miR-146b & $1.11 \pm 1.53$ & $0.9 \pm 0.84$ & 0.1 \\
miR-21 & $0.02 \pm 0.11$ & $0.01 \pm 0.04$ & 0.152 \\
miR-31 & $0.52 \pm 0.76$ & $0.37 \pm 0.49$ & $0.011^{*}$ \\
miR-151-5p & $0.18 \pm 0.25$ & $0.006 \pm 0.09$ & $0.001^{* *}$ \\
miR-221 & $0.14 \pm 0.24$ & $0.01 \pm 0.07$ & $0.003^{* *}$ \\
miR-222 & $2.19 \pm 2.49$ & $0.24 \pm 0.42$ & $0.001^{* *}$ \\
let7e & $0.012 \pm 0.06$ & $0.001 \pm 0.007$ & 0.31 \\
\hline
\end{tabular}

T test, ${ }^{*} \mathrm{p}<0.05,{ }^{* *} \mathrm{p}<0.005$.

Table 4 : Evaluation of the pre- and postoperative serum miRNA levels in the patients according to the stage of the disease.

\begin{tabular}{|c|c|c|c|c|}
\hline \multirow[t]{2}{*}{ PTC group } & & \multirow{2}{*}{$\frac{\text { TNM Stage } 1+2}{\text { Mean } \pm \text { SD }}$} & \multirow{2}{*}{$\begin{array}{l}\text { TNM Stage } 3+4 \\
\text { Mean } \pm \text { SD }\end{array}$} & \multirow[t]{2}{*}{${ }^{+} \mathrm{p}$} \\
\hline & & & & \\
\hline \multirow[t]{3}{*}{ miR-146b } & Preop & $0.35 \pm 0.57$ & $1.36 \pm 2.11$ & 0.175 \\
\hline & Postop & $0.25 \pm 0.25$ & $1.22 \pm 1.20$ & 0.125 \\
\hline & ${ }^{++} \mathrm{p}$ & 0.73 & 0.530 & \\
\hline \multirow[t]{3}{*}{ miR-21 } & Preop & $0.007 \pm 0.02$ & $0.08 \pm 0.25$ & 0.410 \\
\hline & Postop & $0.03 \pm 0.07$ & $0.11 \pm 0.49$ & 0.409 \\
\hline & ${ }^{++} \mathrm{p}$ & 0.3 & 0.172 & \\
\hline \multirow[t]{3}{*}{ miR-31 } & Preop & $0.39 \pm 0.58$ & $0.39 \pm 0.46$ & 0.915 \\
\hline & Postop & $0.21 \pm 0.19$ & $0.54 \pm 0.74$ & 0.586 \\
\hline & ${ }^{++} \mathrm{p}$ & 0.472 & 0.432 & \\
\hline \multirow[t]{3}{*}{ miR-151-5p } & Preop & $0.12 \pm 0.23$ & $0.20 \pm 0.26$ & 0.804 \\
\hline & Postop & $0.01 \pm 0.05$ & $0.008 \pm 0.03$ & 0.629 \\
\hline & ${ }^{++} \mathrm{p}$ & 0.144 & $0.006^{* *}$ & \\
\hline \multirow[t]{3}{*}{ miR-221 } & Preop & $0.15 \pm 0.30$ & $0.12 \pm 0.21$ & 0.827 \\
\hline & Postop & $0.04 \pm 0.13$ & $0.29 \pm 1.31$ & 0.212 \\
\hline & ${ }^{++} \mathrm{p}$ & 0.455 & 0.506 & \\
\hline \multirow[t]{3}{*}{ miR-222 } & Preop & $0.39 \pm 2.89$ & $2.24 \pm 2.39$ & 0.690 \\
\hline & Postop & $0.13 \pm 0.18$ & $0.43 \pm 0.81$ & 0.806 \\
\hline & ${ }^{++} \mathrm{p}$ & 0.097 & $0.003^{* *}$ & \\
\hline \multirow[t]{3}{*}{ let7e } & Preop & $0 \pm 0$ & $0.018 \pm 0.074$ & 0.349 \\
\hline & Postop & $0.002 \pm 0.008$ & $0.001 \pm 0.006$ & 0.629 \\
\hline & ${ }^{++} \mathrm{p}$ & 0.346 & 0.330 & \\
\hline
\end{tabular}

${ }^{+}$Mann-Whitney U test, ${ }^{++} \mathrm{t}$ test, $\quad{ }^{*} \mathrm{p}<0.05,{ }^{* *} \mathrm{p}<0.01$. 


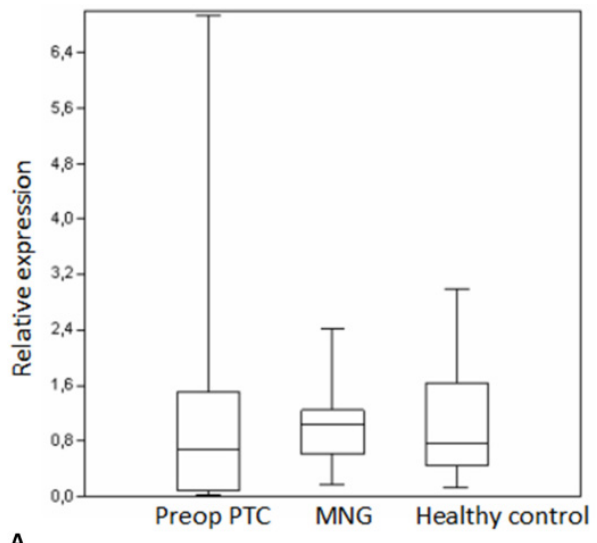

A
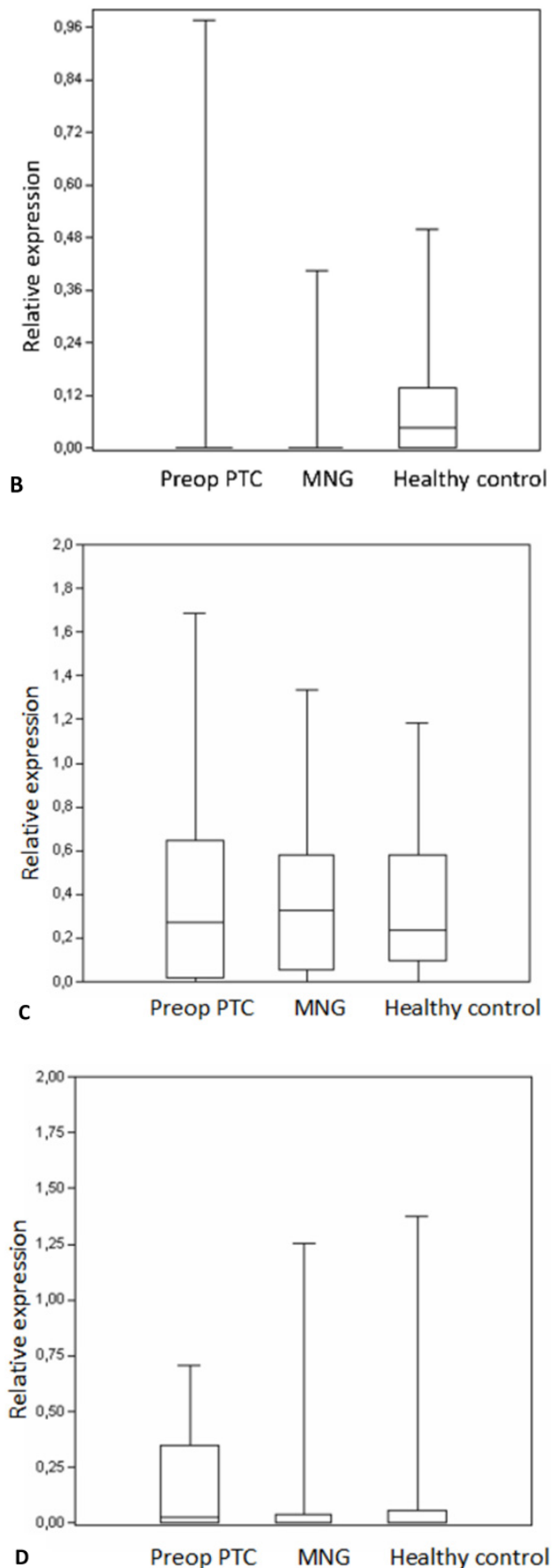
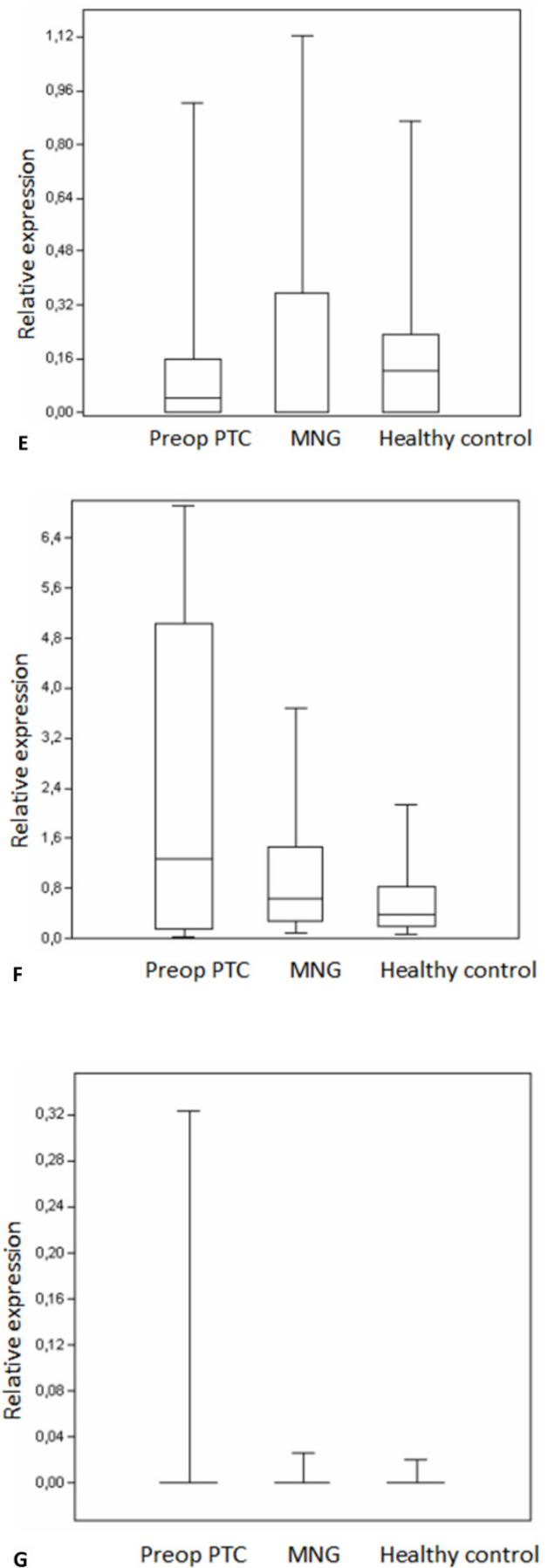

Figure 1: Box plots of miRNA expression levels in sera of patients with PTC MNG and healthy controls. A: miR-146, B: miR-21, C: miR-31, D: miR-151-5p, E: miR-221, F: miR-222, G: let7. The lines inside the boxes indicate the medians. 
Table 5: Evaluation of the pre- and postoperative serum miRNA levels in the patients according to tumor size.

\begin{tabular}{|c|c|c|c|c|}
\hline \multicolumn{2}{|l|}{ PTC Group } & \multirow{2}{*}{$\begin{array}{l}\text { Tumor Diameter }< \\
2 \mathrm{~cm} \\
\text { Mean } \pm \text { SD }\end{array}$} & \multirow{2}{*}{$\begin{array}{l}\text { Tumor Diameter }> \\
2 \mathrm{~cm} \\
\text { Mean } \pm \text { SD }\end{array}$} & \multirow[t]{2}{*}{${ }^{+} \mathrm{p}$} \\
\hline & & & & \\
\hline \multirow[t]{3}{*}{ miR-146b } & Preop & $1.37 \pm 2.59$ & $0.72 \pm 0.60$ & 0.877 \\
\hline & Postop & $0.75 \pm 0.79$ & $1.50 \pm 1.52$ & 0.417 \\
\hline & ${ }^{++} p$ & 0.971 & $0.036^{*}$ & \\
\hline \multirow[t]{3}{*}{$\operatorname{miR}-21$} & Preop & $0.03 \pm 0.14$ & $0.12 \pm 0.32$ & 0.289 \\
\hline & Postop & $0.02 \pm 0.05$ & $0.25 \pm 0.74$ & 0.840 \\
\hline & ${ }^{++} \mathrm{p}$ & 0.686 & 1.000 & \\
\hline \multirow[t]{3}{*}{ miR-31 } & Preop & $0.56 \pm 0.92$ & $0.36 \pm 0.33$ & 0.471 \\
\hline & Postop & $0.30 \pm 0.30$ & $0.73 \pm 1.04$ & 0.980 \\
\hline & ${ }^{++} p$ & 0.687 & 0.779 & \\
\hline \multirow[t]{3}{*}{ miR-151-5p } & Preop & $0.57 \pm 1.62$ & $0.17 \pm 0.23$ & 0.673 \\
\hline & Postop & $0.01 \pm 0.04$ & $0.02 \pm 0.06$ & 0.545 \\
\hline & ${ }^{++} p$ & $0.003^{* *}$ & 0.068 & \\
\hline \multirow[t]{3}{*}{ miR-221 } & Preop & $0.27 \pm 0.82$ & $0.23 \pm 0.28$ & $0.033^{*}$ \\
\hline & Postop & $0.02 \pm 0.09$ & $0.65 \pm 1.96$ & 0.891 \\
\hline & ${ }^{++} p$ & $0.028^{*}$ & 0.237 & \\
\hline \multirow[t]{3}{*}{ miR-222 } & Preop & $2.04 \pm 2.23$ & $2.49 \pm 2.64$ & 0.643 \\
\hline & Postop & $0.34 \pm 0.74$ & $0.37 \pm 0.66$ & 0.539 \\
\hline & ${ }^{++} \mathrm{p}$ & $0.003^{* *}$ & $0.017^{*}$ & \\
\hline \multirow[t]{3}{*}{ let7e } & Preop & $0.018 \pm 0.076$ & $0.004 \pm 0.011$ & 0.651 \\
\hline & Postop & $0.003 \pm 0.008$ & $0 \pm 0$ & 0.322 \\
\hline & ${ }^{++} p$ & 1.000 & 0.317 & \\
\hline
\end{tabular}

+Mann-Whitney U test, ${ }^{++} \mathrm{t}$ test, ${ }^{*} \mathrm{p}<0.05,{ }^{* *} \mathrm{p}<0.01$.

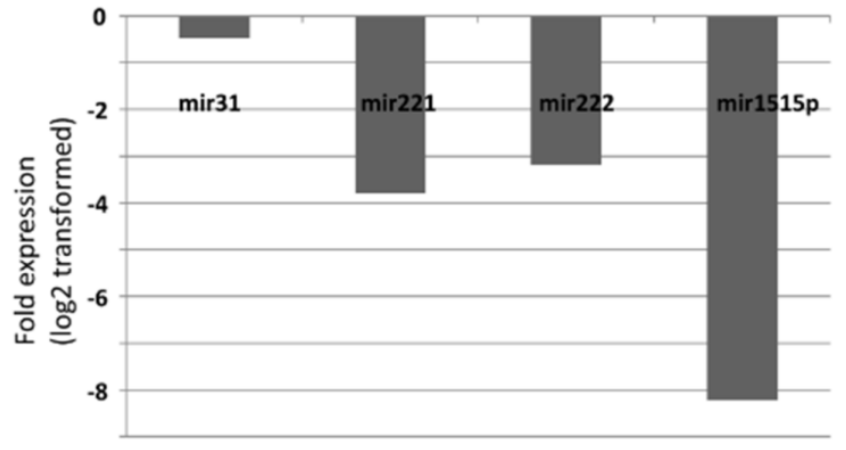

Figure 2: Expression changes of the miRNA levels in the posterative versus preoperative sera.

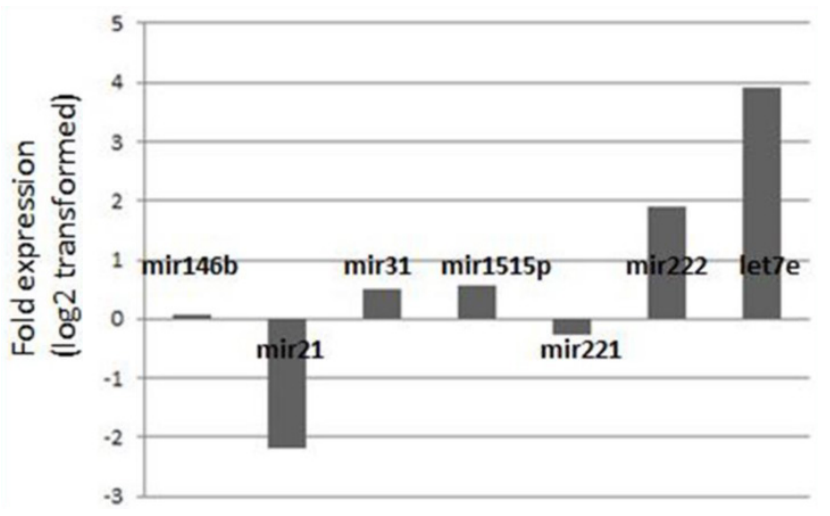

Figure 3: Fold-change profiles of microRNAs in papillary thyroid carcinoma versus healthy controls. Data represent the medians of relative miRNA levels (log2 transformed).

diagnosis or can predict prognosis of PTC. In this study we analyzed a panel of miRNAs in terms of their utility in the differential diagnosis of thyroid cancer and their association with the clinical parameters as potential biomarkers for the disease.

miR-21 has been reported to aid in distinguishing the papilary tumor variants in a selected miRNA panel [26]. In our study circulating miR-21 levels were downregulated both in the patients with PTC and benign thyroid disease compared to the healthy individuals. In an earlier study higher levels of miR-21 have been reported in tumor tissue when compared to normal tissue [27]. It has also been suggested that higher miR-21 expression levels are detected in PTC tissue samples when compared to MG [28]. This was not the case in our study. However, these previous studies comprised nine and ten patients, respectively and our sample size is three times greater. Although upregulation of miR-21 in the patients has been reported in some studies other reports failed to confirm this and decreased expression in the plasma has also been reported in subgroups of tumors [29]. Furthermore, our data is in accordance with a very recent report which has found significantly decreased 
miR-21 levels in papillary thyroid cancer [30]. miR-221 and miR-222 are overexpressed in PTC $[27,31]$ and have been associated with aggressive tumors and adverse clinical characteristics [24,32,33]. High levels of miR-146b and miR-222 have been reported in aggressive papillary thyroid cancer $[24,34,35]$. Evaluation of the pre- and postoperative groups showed that miR-221 and miR-222 levels were significantly lower after surgery. A significant decline was also observed following resection of the tumors in patients with Stage III/IV disease for miR-222. Combined with the fact that preoperative miR-221 levels are higher in tumors that are smaller than $2 \mathrm{~cm}$ when compared to larger tumors this may indicate that miR-221 and miR-222 expression levels in the circulation may be associated with the tumor burden. This conclusion is in accordance with previous studies $[27,36]$ and with a report suggesting that miR-222 is important for detecting recurrence in PTC [32]. While postoperative miR-222 levels were lower for all tumors a significant decline of the postoperative miR-221 levels was observed only in tumors smaller than $2 \mathrm{~cm}$. These findings support previous reports suggesting that miR-221 is one of the most sensitive miRNA molecules for thyroid cancer [37].

Microarray data suggest that miR-146b is overexpressed in many cancer types, such as melanoma [38], lung [39] and colorectal cancer [40]. The miR-146b molecule plays an important role in tumor progression by downregulating BRCA1 [41]. We observed higher postoperative miR-146b levels in patients with tumors larger than $2 \mathrm{~cm}$. This is in line with studies suggesting that miR-146b levels in fine needle aspiration biopsies may help in detecting and identifying thyroid cancer [14,24,42]. Our data support the observations that miR-146b is associated with the risk of recurrence and may promote cell migration and invasion [35]. This finding is also consistent with the fact that an association with tumor size has been shown for several miRNA molecules [32].

miR-31 and let7e molecules have been characterized as tumor suppressors in different cancer types $[25,43,44]$. Deregulation of let-7 is observed in different types of cancer. Let- 7 genes are known to be highly expressed in the thyroid gland $[20,45]$ and let-7 downregulation has been associated with thyroid tumors $[30,46]$. Serum miR-31 expression levels were not different between the disease and the control groups. A study has suggested that higher miR-31 expression is observed in tissue biopsy samples from oncocytic adenomas [24]. In our study neither the PTC nor the MG samples displayed aberrant miR-31 expression. This is in concordance with a recent study which has not found differential expression of miR-31 between the normal tissue and thyroid tumors [47]. Although much higher let-7 levels were observed in the patients with PTC the difference was not significant possibly due to the wide distribution of the values. However, discrepant expression of let-7 is also consistent with a previous study [19].

miR-151-5p has been implicated in several pathological conditions as well as cancer [48], and was found to be correlated with the migration and invasion of cancer cells [49]. Evaluation of the preand postoperative groups showed significantly lower miR-151-5p levels in postoperative patients with late stage tumors. This is in concordance with a previous study reporting a significant decrease of the miR-151-5p levels following tumor excision and is also in line with the suggestion that miR-151-5p is associated with lymph node metastasis and larger tumor size [19].

In conclusion, in this study we demonstrate that a specific set of differentially expressed miRNAs are detected in the circulation of patients with papillary thyroid cancer. Several studies have shown a clear agreement between the miRNA levels in serum and tumor tissue in paired samples from different tumors in general [50,51] and in thyroid carcinoma in particular [19]. Therefore, we suggest that miRNA expression profiling may have diagnostic value and help to monitor the progress of PTC. Long-term follow-up of the patients in the current study and studies in larger cohorts are necessary to prove the utility of these molecules in terms of clinical practice as biomarkers.

\section{Acknowledgments}

This work was supported by the Istanbul University Research Fund (Project number: 32227).

\section{Competing interests}

The authors declare that they have no competing interests.

\section{References}

1. Siegel R, Naishadham D, Jemal A. Cancer Statistics. CA Cancer J Clin. 2012; 62: 10-29.

2. Eszlinger M, Paschke R. Molecular fine-needle aspiration biopsy diagnosis of thyroid nodules by tumor specific mutations and gene expression patterns. Mol Cell Endocrinol. 2010; 322: 29-37.

3. Ferraz C, Eszlinger M, Paschke R. Current state and future perspective of molecular diagnosis of fine-needle aspiration biopsy of thyroid nodules. J Clin Endocrinol Metab. 2011; 96: 2016-2026.

4. Prasad NB, Somervell H, Tufano RP, et al. Identification of genes differentially expressed in benign versus malignant thyroid tumors. Clin Cancer Res. 2008; 14: 3327-3337.

5. Verburg FA Reiners C. The association between multinodular goiter and thyroid cancer. Minerva Endocrinol. 2010; 35: 187-192.

6. Schneider DF, Chen HCA. New developments in the diagnosis and treatment of thyroid cancer. Cancer J Clin. 2013; 63: 374-394.

7. Kouniavsky G, Zeige MA. Thyroid tumorigenesis and molecular markers in thyroid cancer. Curr Opin Oncol. 2010; 22: 23-29.

8. Pita JM, Figueiredo IF, Moura MM, et al. Cell cycle deregulation and TP53 and RAS mutations are major events in poorly differentiated and undifferentiated thyroid carcinomas. J Clin Endocrinol Metab. 2014; 13: jc20131512. 
9. Guerra A, Di Crescenzo V, Garzi A, et al. Diagnostic utility of BRAFV600E mutation testing in thyroid nodules in elderly patients. BMC Surg. 2013; 13(Suppl 2): S37.

10. de Biase D, Visani M, Pession A, et al. Molecular diagnosis of carcinomas of the thyroid gland. Front Biosci. 2014; 6: 1-14.

11. Bryant RJ, Pawlowski T, Catto JW, et al. Changes in circulating microRNA levels associated with prostate cancer. Br J Cancer. 2012; 106: 768-74.

12. Creemers EE, Tijsen AJ, Pinto YM. Circulating microRNAs: novel biomarkers and extracellular communicators in cardiovascular disease? Circ Res. 2012; 110: 483-495.

13. Yuxia M, Zhennan T, Wei Z. Circulating miR-125b is a novel biomarker for screening non-small-cell lung cancer and predicts poor prognosis. J Cancer Res Clin Oncol. 2012; 138: 2045-2050.

14. Chen YT, Kitabayashi N, Zhou XK, et al. MicroRNA analysis as a potential diagnostic tool for papillary thyroid carcinoma. Mod Pathol. 2008; 21: 1139-1146.

15. Brase JC, Wuttig $D$, Kuner $R$, et al. Serum microRNA as non-invasive biomarkers for cancer. Mol Cancer. 2010; 9: 306.

16. Huang $\mathrm{Z}$, Huang $\mathrm{D}, \mathrm{Ni} \mathrm{S}$, et al. Plasma microRNA are promising novel biomarkers for early detection of colorectal cancer. Int J Cancer. 2010; 127: $118-126$

17. Weber F, Teresi RE, Broelsch CE, et al. A limited set of human microRNA is deregulated in follicular thyroid carcinoma. J Clin Endocrinol Metabol. 2006; 91: 3584-3591.

18. Visone $\mathrm{R}$, Pallante $\mathrm{P}$, Vecchione A, et al. Specific microRNAs are downregulated in human thyroid anaplastic carcinomas. Oncogene. 2007; 26: 7590-7595.

19. Yu S, Liu Y, Wang J, et al. Circulating MicroRNA Profiles as Potential Biomarkers for Diagnosis of Papillary Thyroid Carcinoma. J Clin Endocrinol Metab. 2012; 97: 2084-2092.

20. Fuziwara CS, Kimura ET. MicroRNA Deregulation in Anaplastic Thyroid Cancer Biology. Int J Endocrinol. 2014; 2014: 743450.

21. Dettmer M, Vogetseder A, Durso MB, et al. MicroRNA expression array identifies novel diagnostic markers for conventional and oncocytic follicular thyroid carcinomas. J Clin Endocrinol Metab. 2013; 98: E1-7.

22. Zhang J, Yang Y, Liu Y, et al. MicroRNA-21 regulates biological behaviors in papillary thyroid carcinoma by targeting programmed cell death 4 . J Surg Res. 2014; 189: 68-74.

23. Stokowy T, Wojtaś B, Fujarewicz K, et al. miRNAs with the potential to distinguish follicular thyroid carcinomas from benign follicular thyroid tumors: results of a meta-analysis. Horm Metab Res. 2014, 46: 171-80.

24. Nikiforova MN, Tseng GC, Steward D, et al. MicroRNA expression profiling of thyroid tumors:biological significance and diagnostic utility. J Clin Endocrinol Metab. 2008, 93: 1600-1608.

25. Li X, Abdel-Mageed AB, Mondal $\mathrm{D}$, et al. MicroRNA expression profiles in differentiated thyroid cancer, a review. Int J Clin Exp Med. 2013; 6: 74-80.

26. Sheu SY, Grabellus F, Schwertheim S, et al. Differential miRNA expression profiles in variants of papillary thyroid carcinoma and encapsulated follicular thyroid tumours. Br J Cancer. 2010; 102: 376-382

27. He H, Jazdewski K, Li W, et al. The role of microRNA genes in papillary thyroid carcinoma. Proc Natl Acad Sci USA. 2005; 102: 19075-19080.

28. Tetzlaff MT, Liu A, Xu X, et al. Differential expression of miRNAs in papillary thyroid carcinoma compared to multinodular goiter using formalin fixed paraffin embedded tissues. Endocr Pathol. 2007; 18: 163-173.

29. Heegard NH, Schetter AJ, Welsh JA et al. Circulating microRNA expression profiles in early stage nonsmall cell lung cancer. Int J Cancer. 2012; 130: 1378-1386.

30. Sondermann A, Andreghetto FM, Moulatlet AC et al. MiR-9 and miR-21 as prognostic biomarkers for recurrence in papillary thyroid cancer. Clin Exp Metastasis. 2015; 32: 521-530

31. Pallante P, Visone R, Ferracin M, et al. MicroRNA deregulation in human thyroid papillary carcinomas. Endocr Relat Cancer. 2006; 13: 497-508.

32. Lee JC, Zhao JT, Clifton-Bligh RJ, et al. MicroRNA-222 and microRNA $146 \mathrm{~b}$ are tissue and circulating biomarkers of recurrent papillary thyroid cancer. Cancer. 2013; 119: 4358-4365.

33. Wang Z, Zhang H, He L, et al. Association between the expression of four upregulated miRNAs and extrathyroidal invasion in papillary thyroid carcinoma. Onco Targets Ther. 2013; 6: 281-287.

34. Yip L, Kelly L, Shuai Y, et al. MicroRNA signature distinguishes the degree of aggressiveness of papillary tyhroid carcinoma. Ann Surg Oncol. 2011; 18: 2035-2041.

35. Chou CK, Yang KD, Chou FF, et al. Prognostic implications of miR-146b expression and its functional role in papillary thyroid carcinoma. J Clin Endocrinol Metab. 2013; 98: E196-205.

36. Visone R, Russo L, Pallante P, et al. MicroRNAs(miR)-221 and miR-222, both overexpressed in human thyroid papillary carcinomas, regulate p27Kip1 protein levels and cell cycle. Endocr Relat Cancer. 2007; 14: 791-798.

37. Mazeh H, Mizrahi I, Halle D, et al. Development of a microRNA-based molecular assay for the detection of papillary thyroid carcinoma in aspiration biopsy samples. Thyroid. 2011; 21: 111-118.

38. Jukic DM, Rao UN, Kelly L, et al. MicroRNA profiling analysis of differences between the melanoma of young adults and older adults. J Transl Med. 2010; 8: 27.
39. Patnaik SK, Kannisto E, Mollick R, et al. Overexpression of the lung cancer-prognostic miR-146b miRNAs has a minimal and negative effect on the malignant phenotype og A549 cancer cells. PLos One 2011; 6: e22379.

40. Ragusa M, Majorana A, Statello L, et al. Specific alterations of microRNA transcriptome and global network structure in colorectal carcinoma after cetuximab treatment. Mol Cancer Ther. 2010; 9: 3396-3409.

41. Garcia A, Buisson M, Bertrand P, et al. Down-regulation of BRCA1 expression by miR-146a and miR-146b-5p in triple negative sporadic breast cancers. EMBO Mol Med. 2011; $3: 279-290$

42. Shen $\mathrm{R}$, Liyanarachchi $\mathrm{S}, \mathrm{Li} \mathrm{W}$, et al. MicroRNA signature in thyroid fine needle aspiration cytology applied to "atypia of undetermined significance" cases. Thyroid. 2012; 22: 9-16.

43. Mayr C, Hemann MT, Bartel DP. Disrupting the pairing between let-7 and Hmga2 enhances oncogenic transformation. Science. 2007; 315: 1576-1579.

44. Fuse M, Kojima S, Enokida H, et al. Tumor suppressive microRNAs (miR-222 and miR-31) regulate molecular pathways based on microRNA expression signature in prostate cancer. J Hum Genet. 2012; 57: 691-699.

45. Marini F, Luzi E, Brandi ML. MicroRNA Role in Thyroid Cancer Development. J Thyroid Res. 2011; 2011: 407123.

46. Colamaio M, Calì G, Sarnataro D, et al. Let-7a down-regulation plays a role in thyroid neoplasias of follicular histotype affecting cell adhesion and migration through its ability to target the FXYD5 (Dysadherin) gene. J Clin Endocrinol Metab. 2012; 97: E2168-78.

47. Suresh R, Sethi S, Ali S et al. Differential expression of microRNAs in papillary thyroid carcinoma and their role in racial disparity. J Cancer Sci Ther. 2015; 7: 145-154.

48. Krell J, Frampton AE, Jacob J et al. The clinico-pathologic role of microRNAs miR-9 and miR-151-5p in breast cancer. Mol Diagn Ther. 2012; 16: 167-172.

49. Ding J, Huang S, Wu S et al. Gain of miR-151 on chromosome 8q24.3 facilitates tumor cell migration and spreading through downregulating RhoGDIA. Nat Cell Biol. 2010; 12: 390-399.

50. Tang BB, Liu SY, Zhan YU, et al. MicroRNA-218 expression and its association with the clinicopathological characteristics of patients with cervical cancer. Exp Ther Med. 2015; 10: 269-274.

51. Wang $\mathrm{L}$, Liu $\mathrm{M}$, Zhu $\mathrm{H}$, et al. Identification of recurrence-related serum microRNAs in hepatocellular carcinoma following hepatectomy. Cancer Biol Ther. 2015; 15: 1-8. 